\title{
Charge-transfer complexes of arene-molybdenum-tricarbonyl complexes as heterogeneous metathesis catalysts for the polymerization of phenylacetylene
}

\author{
M. Belen Mula, Andrew J. Beaumont, Kevin O. Doyle, M. Louise Gallagher, \\ A. Denise Rooney \\ Department of Chemistry, National University of Ireland, Maynooth, Kildare, Ireland \\ Received 5 November 1998; received in revised form 7 January 1999; accepted 7 January 1999
}

\begin{abstract}
Charge-transfer complexes were precipitated from benzene solutions of arene-metal-tricarbonyl $(\mathrm{M}=\mathrm{Cr}$, Mo $)$ and a series of electron acceptors. The complexes were characterised by IR spectroscopy. The charge-transfer complexes of (arene) $\mathrm{Mo}(\mathrm{CO})_{3}$ with 2,3,5,6-tetrachloro-1,4-benzoquinone (chloranil) and with 2,3,5,6-tetrabromo-1,4-benzoquinone (bromanil) were found to be very active catalysts for the polymerization of phenylacetylene, whereas the charge-transfer complexes of the same organometallic but with 2,3,5,6-tetrafluoro-1,4-benzoquinone (fluoranil), 2,3-dichloro-5,6-dicyano1,4-benzoquinone (DDQ), and tetracyanoethene (TCNE) had very little activity. The analogous chromium systems were also inactive. Theoretical calculations were carried out to examine a relationship between the stability of the charge-transfer complex and its catalytic activity. (C) 1999 Elsevier Science B.V. All rights reserved.
\end{abstract}

Keywords: Metathesis; Polymerization; Charge-transfer complexes; Molybdenum

\section{Introduction}

Studies on the ability of (arene) $\mathrm{M}(\mathrm{CO})_{3}$ to catalyse the polymerization of phenylacetylene have shown that high temperatures are required in order to achieve reasonable yields, and that the molybdenum catalysts are the most active [1]. The mechanism for this reaction is wellestablished and is proposed to occur via a 'ring slip' mechanism whereby the hapticity to the arene ring decreases from $\eta^{6}$ to $\eta^{2}$ in order to

\footnotetext{
* Corresponding author. Tel.: + 353-1-708-3770; Fax: + 353-1708-3815; E-mail: ad.rooney@may.ie
}

allow two phenylacetylene monomer units to bind to the metal [1]. Recently, there have been reports in the literature of the development of a very active homogeneous metathesis catalyst for the polymerization of phenylacetylene producing reasonably high molecular weight polymers ( $M_{n}$ 15000-25000) [2]. This catalyst involved the oxidation of (arene)Mo(CO) ${ }_{3}$ complexes using 2,3,5,6-tetrachloro-1,4-benzoquinone (chloranil). The intermediate proposed to be involved in this catalysis was a charge-transfer complex leading to the completely charge separated ion-pair in solution. The 17-electron [(arene)$\left.\mathrm{Mo}(\mathrm{CO})_{3}\right]^{+}$was proposed to be the catalytically 
active species as it is well-established that oddelectron organometallic complexes have increased reactivity compared to their 18-electron precursors, and such species have been shown to be active in polymerization reactions $[3,4]$. The study found that molybdenum complexes were active whereas the analogous chromium complexes were not, and that of the range of electron acceptors tested only chloranil formed an active catalyst. In order to explain this behaviour, it was suggested that inactivity occurred in systems in which a charge-transfer intermediate was not formed. However, there is significant precedent in the literature that (arene) $\mathrm{M}(\mathrm{CO})_{3}(\mathrm{M}=\mathrm{Cr}$, Mo, W) complexes can form stable charge-transfer complexes with electron acceptors of this type [5-9]. In fact, a crystal structure for (anisole) $\mathrm{Cr}(\mathrm{CO})_{3}$-1,3,5,-trinitrobenzene was determined by Huttner et al. [5] in 1966. In this study, we set out to form and characterise charge-transfer complexes from (arene) $\mathrm{M}(\mathrm{CO})_{3}(\mathrm{M}=\mathrm{Mo}, \mathrm{Cr})$ and test these complexes for their ability to catalyse phenylacetylene polymerization.

\section{Experimental}

\subsection{Instrumentation}

IR spectra of the solid samples in $\mathrm{KBr}$ were recorded on a Nicolet FT Impact 400D spectrometer. UV/Vis spectra were recorded on a Milton Roy 3000 Array spectrometer. Molecular weights were determined using gel permeation chromatography. Samples were dissolved in chlorobenzene (15 $\mathrm{mg}$ in $2 \mathrm{~cm}^{3}$ ) and filtered through a $0.45 \mu \mathrm{m}$ Teflon syringe filter prior to injection. Molecular weights were measured relative to polystyrene. The LUMO energies of the electron acceptors were calculated using CAChe for Windows from Oxford Molecular. This includes the package MOPAC 6.0 for semi-empirical molecular orbital calculations using the methods AM1 and PM3.

The irradiation was carried out using a 1000 W Oriel xenon arc lamp (model 66023)

\subsection{Synthesis of the charge-transfer complexes}

All reactions were carried out using standard Schlenk techniques unless otherwise stated.

\subsubsection{Method 1}

Arene $\mathrm{M}(\mathrm{CO})_{3}(0.17 \mathrm{mmol})$ and the desired electron acceptor $(0.17 \mathrm{mmol})$ were added to dry degassed benzene solvent $\left(5 \mathrm{~cm}^{3}\right)$ and stirred until a black precipitate of the corresponding charge-transfer complex was formed. This could take from several seconds to several hours depending upon the compounds used. The charge-transfer complexes were characterised using IR spectroscopy. The $v(\mathrm{CO})_{\text {sym }}$ band (Table 1) in the IR spectra of the black complexes corresponds well with those of charge-transfer complexes formed from (arene) $\mathrm{M}(\mathrm{CO})_{3}$ reported in the literature, in that the band is essentially unchanged in wavenumber upon reaction with the electron acceptor [5,7]. The $\nu(\mathrm{CO})$ of the substituted 1,4-benzoquinones was observed to shift downwards in wavenumber in the black precipitate. This is consistent with the quinone accepting electron density onto the ring causing the bond order of the organic carbonyls to decrease.

Problems arose when trying to characterise the black precipitates in solution using $\mathrm{UV} / \mathrm{Vis}$ spectroscopy. The Schlenk UV/Vis cuvette has

Table 1

CO stretching frequencies for charge-transfer complexes of (mesitylene)Mo(CO) ${ }_{3}$ and substituted 1,4-benzoquinones

\begin{tabular}{lll}
\hline Compound $^{\mathrm{a}}$ & $\begin{array}{l}\text { Metal carbonyl } \\
\nu(\mathrm{CO})_{\mathrm{sym}} \mathrm{cm}^{-1}\end{array}$ & $\begin{array}{l}\text { Quinone } \\
\nu(\mathrm{CO}) \mathrm{cm}^{-1}\end{array}$ \\
\hline $\begin{array}{l}\text { (Mesitylene) } \\
\begin{array}{l}\text { Mo(CO) } 3^{-} \\
\text {fluoranil }\end{array}\end{array}$ & 1956 & 1529 \\
$\begin{array}{l}\text { Fluoranil } \\
\text { (Mesitylene) }\end{array}$ & 1956 & 1700 \\
$\begin{array}{l}\text { Mo(CO) } 3^{-} \\
\text {chloranil }\end{array}$ & & 1411 \\
$\begin{array}{l}\text { Chloranil } \\
\text { (Mesitylene) }\end{array}$ & 1956 & \\
$\begin{array}{l}\text { Mo(CO) } \\
3^{-}\end{array}$ & & 1685 \\
bromanil & & 1381 \\
Bromanil & & \\
\hline
\end{tabular}

${ }^{\mathrm{a}}$ Spectra recorded in $\mathrm{KBr}$. 
a pathlength of $1 \mathrm{~cm}$ and the charge-transfer band of the complexes in dichloromethane was too intense to be measured. However, upon dilution the solution turned from a dark green or blue to yellow and the UV/Vis spectrum of the starting materials was recorded. This is wellestablished behaviour of charge-transfer complexes that they dissociate to form their constituent species upon dilution [5]. The black precipitates were generally insoluble in nonpolar solvents but very soluble in polar solvents such as ether, ethanol, methanol and water. The black precipitate dissolved in methanol to form a yellow solution and in dichloromethane to form a purple solution. This observation is typical behaviour for charge-transfer complex; the complex separates into the ions in the highly polar solvents and the lower energy chargetransfer transition is lost [10].

\subsubsection{Method 2}

(Mesitylene) $\mathrm{Mo}(\mathrm{CO})_{3}$ and chloranil were ground together and the mixture was heated at $60^{\circ} \mathrm{C}$ under vacuum for several minutes until the bright yellow mixture had turned black [5].

\subsection{Typical polymerization procedure}

Phenylacetylene (2 ml, $18 \mathrm{mmol}$ ) was added to the heterogeneous mixture of charge-transfer solid and benzene solvent. The sample was shaken at room temperature for 20 min after which the reaction mixture was poured into excess ethanol in order to precipitate the polyphenylacetylene formed, which was then purified by recrystallisation from chloroform. The polymers formed had a molecular weight in the region of $M_{n}$ 2000, which compared well with the values obtained previously in the literature [1].

\section{Results and discussion}

Charge-transfer complexes of a range of (arene) $\mathrm{M}(\mathrm{CO})_{3}$ complexes and electron accep- tors were precipitated from benzene (Section 2.2.1). The charge-transfer complexes were then tested in situ for their catalytic activity with respect to the polymerization of phenylacetylene (Table 2).

Our finding that charge-transfer is important in producing a catalytically active species is in agreement with previous studies [2]. For example, 1,4-benzoquinone and 2,3,5,6-tetramethyl1,4-benzoquinone do not form charge-transfer complexes when added to (mesitylene)Mo$(\mathrm{CO})_{3}$, and these systems do not catalyse the formation of polyphenylacetylene. However, the results of our experiments indicated that, contrary to what has previously been suggested in the polymerization study, but in agreement with previous studies on the ability of (arene) $\mathrm{M}(\mathrm{CO})_{3}$ to form charge-transfer complexes, chargetransfer complexes were formed in most cases [5-9]. However, only the charge-transfer complexes formed by chloranil and 2,3,5,6-tetrabromo-1,4-benzoquinone (bromanil) with a certain number of the molybdenum complexes showed significant catalytic activity. Moreover, since the polar charge-transfer complexes were highly insoluble in benzene, it indicates that the catalyst is actually heterogeneous in nature.

Tests were then carried out on the (mesitylene) $\mathrm{Mo}(\mathrm{CO})_{3}$-chloranil and -bromanil systems for the effects of oxygen and water on their catalytic activity. The charge-transfer complex was formed as above (Section 2.2.1) and then the sample was opened to the air and non-degassed phenylacetylene was added. The catalysts still produced nearly $100 \%$ of polymer but now the time taken to complete the reaction was approximately $10 \mathrm{~min}$. These findings indicate that the catalytic activity of the complex is not inhibited by the presence of air. This is in agreement with the work of Fischer who showed that charge-transfer complexes of this type are stable in the solid state but very air sensitive in solution [5]. However, if $1 \mathrm{~cm}^{3}$ of water was added to the benzene, causing the black precipitate to dissolve, the polymerization reaction was inhibited leading to the formation of about $20 \%$ 
Table 2

The ability of (arene) $\mathrm{M}(\mathrm{CO})_{3}(\mathrm{M}=\mathrm{Cr}, \mathrm{Mo})$ to form charge-transfer complexes and the activity of the complexes as metathesis catalysts

\begin{tabular}{|c|c|c|c|c|}
\hline Electron acceptor & Organometallic complex & $\begin{array}{l}\text { Colour change in solution } \\
\text { upon addition of } \\
\text { electron acceptor }\end{array}$ & Precipitate formed & Yield of polymer formed \\
\hline Bromanil & (Mesitylene) $\mathrm{Mo}(\mathrm{CO})_{3}$ & dark green & black ppt & $91 \%$ \\
\hline Chloranil & (Mesitylene) $\mathrm{Mo}(\mathrm{CO})_{3}$ & dark green & black ppt & $92 \%$ \\
\hline Fluoranil & (Mesitylene) $\mathrm{Mo}(\mathrm{CO})_{3}$ & blue & black ppt & $7 \%$ \\
\hline TCNE & (Mesitylene) $\mathrm{Mo}(\mathrm{CO})_{3}$ & blue & black ppt & none \\
\hline Quinone & (Mesitylene) $\mathrm{Mo}(\mathrm{CO})_{3}$ & no colour change & none & none \\
\hline Tetramethylquinone & (Mesitylene) $\mathrm{Mo}(\mathrm{CO})_{3}$ & no colour change & none & none \\
\hline DDQ & (Mesitylene) $\mathrm{Mo}(\mathrm{CO})_{3}$ & & $\begin{array}{l}\text { black ppt forms } \\
\text { instanteously no } \\
\text { colour change observed }\end{array}$ & $5 \%$ \\
\hline Chloranil & (Toluene)Mo(CO) $)_{3}$ & green & black ppt & $92 \%$ \\
\hline Bromanil & (Toluene) $\mathrm{Mo}(\mathrm{CO})_{3}$ & green & black ppt & $91 \%$ \\
\hline Fluoranil & (Toluene) $\mathrm{Mo}(\mathrm{CO})_{3}$ & dark blue & black ppt & none \\
\hline TCNE & (Toluene)Mo(CO) ${ }_{3}$ & blue & black ppt & none \\
\hline Chloranil & (Benzene) $\mathrm{Mo}(\mathrm{CO})_{3}$ & green & black ppt & $91 \%$ \\
\hline Chloranil & (Acenaphthalene) $\mathrm{Mo}(\mathrm{CO})_{3}$ & purple & black ppt & none \\
\hline Fluoranil & (Acenaphthalene)Mo(CO) $)_{3}$ & dark brown & black ppt & none \\
\hline Chloranil & (Mesitylene) $\mathrm{Cr}(\mathrm{CO})_{3}$ & green & none & none \\
\hline Bromanil & (Mesitylene) $\mathrm{Cr}(\mathrm{CO})_{3}$ & green & none & none \\
\hline Fluoranil & (Mesitylene) $\mathrm{Cr}(\mathrm{CO})_{3}$ & dark blue & black ppt & none \\
\hline
\end{tabular}

of the original yield of polymer. As dissolution of the charge-transfer complex inhibited its catalytic activity this finding would support our suggestion that the polymerization is taking place via heterogeneous catalysis and involves the charge-transfer complex itself and not the completely charge separated ion-pair in solution. This proposal is supported by a previous study on the (arene)Cr(CO) $)_{3}$ with TCNE and 1,3,5-trinitrobenzene in 1,2-dichloroethane which recorded no ESR signal for the chargetransfer complexes, indicating that complexes of this type do not undergo charge separation even in solvents of reasonable polarity [6]. The proposal that the metathesis reaction is heterogeneously catalysed would explain the observation noted in the literature that this catalytic system exhibited much lower activity in polar solvents such as diethyl ether, which would be expected to enhance ion-pairing [11]. In fact, the equilibrium constants for formation of charge-transfer complexes of this type are quite low, suggesting that in non-polar solutions such as benzene, the charge-transfer solid is in equilibrium with the starting compounds and not the ion-pair [7].
Although we suggest that the catalysis is actually heterogeneous, the presence of the solvent must be important as our attempts to isolate the charge-transfer complex and use it as a catalyst failed. Catalytic activity of the (mesitylene) $\mathrm{Mo}(\mathrm{CO})_{3}$-chloranil charge-transfer complex is seriously reduced if it is separated from the benzene solvent (15\% conversion after $2 \mathrm{~h}$ shaking at room temperature) and is completely inhibited if the charge-transfer complex is dried under vacuum. Moreover, the catalyst loses its activity if stored in the presence of the benzene solvent for approximately $24 \mathrm{~h}$.

In a separate experiment, the charge-transfer complex (mesitylene)Mo(CO) ${ }_{3}$-chloranil was formed in the solid state in an adaptation of the method described by Fischer (Section 2.2.2) [5]. The IR spectrum was identical to the black precipitate formed from the same starting materials in benzene solution. Dry degassed benzene $\left(5 \mathrm{~cm}^{3}\right)$ was then added over this insoluble black compound and phenylacetylene $\left(2 \mathrm{~cm}^{3}\right)$ was added. The mixture was stirred at room temperature for $1 \mathrm{~h}$ at which time $20 \%$ yield of polymer was formed. Although this is a lower 
activity than when the [5] charge-transfer complexes were formed by precipitation from solution, it has a significantly higher activity than (mesitylene) $\mathrm{Mo}(\mathrm{CO})_{3}$ alone. This confirms the importance of electron transfer in enhancing the catalytic activity of (mesitylene) $\mathrm{Mo}(\mathrm{CO})_{3}$, and it is likely that the method employed here simply does not form the charge-transfer complexes with as high efficiency.

A possible reason for the enhanced catalytic activity of the charge-transfer complexes compared to the (arene) $\mathrm{M}(\mathrm{CO})_{3}$ precursors is that they undergo a more facile reduction in the arene ring hapticity. This proposal is backed up by the following experimental observation. The lowest energy electronic transition of (arene)$\mathrm{M}(\mathrm{CO})_{3}$ complexes has been assigned to a metal-to-arene charge-transfer, therefore, promotion into this excited state mimics the charge-transfer complex in that electron density is taken from the metal based HOMO and placed on the arene ring [12]. Phenylacetylene $\left(2 \mathrm{~cm}^{3}\right.$, $1.88 \mathrm{~g}$ ) was added to a solution of (mesitylene)$\mathrm{Mo}(\mathrm{CO})_{3}(90 \mathrm{mg})$ in benzene $\left(10 \mathrm{~cm}^{3}\right)$. The solution was irradiated for $4 \mathrm{~h}$ at wavelengths greater than $400 \mathrm{~nm}$ populating the chargetransfer excited state and polyphenylacetylene was formed in a $25 \%$ yield. This is the first report that these complexes can undergo photoinduced polymerization reactions using visible light. That polymerization could be induced using irradiation wavelengths which are very inefficient at producing $\mathrm{CO}$ loss from (mesitylene $) \mathrm{Mo}(\mathrm{CO})_{3}$ indicates that another mechanism must be occurring [13]. A photochemical study on a related complex (pyridine) $\mathrm{Cr}(\mathrm{CO})_{3}$ shows that irradiation into the lowest energy metal-arene charge-transfer band results in a change of the arene ring hapticity form $\eta^{6}$ to $\eta^{1}$ [14]. Thus, indicating that a transfer of electron density from the metal to the arene promotes 'ring slippage'.

Our findings would indicate that chargetransfer complexes are important in the catalytic activity of these systems but that not all the charge-transfer complexes show this activity. It is not surprising that the chromium compounds are not active, as chromium systems are generally poor metathesis catalysts [15]. That the polymerisation of phenylacetylene involves a metal carbene intermediate is confirmed by the observation that the active systems can also polymerize norbornene. For the molybdenum complexes, we observed that those which form a green solution before forming the black precipitate were catalytically active while those that form a blue solution are not. This would suggest that the more stable charge-transfer complexes are not catalytically active. This proposal is supported by the theoretical calculations on the energies of the lowest unoccupied molecular orbitals of the electron acceptors. The energies of the LUMOs of the substituted 1,4-benzoquinones provide a measure of their ability to act as electron acceptors in the formation of a charge-transfer complex with (arene) $\mathrm{Mo}(\mathrm{CO})_{3}$. The LUMO energies of the substituted 1,4-benzoquinones have been calculated using the semi-empirical methods AM1 and PM3 (Table 3).

There is a clear correlation between the AM1 and PM3 LUMO energies of the quinones, their ability to form charge-transfer complexes with (mesitylene) $\mathrm{Mo}(\mathrm{CO})_{3}$, and the ability of the charge-transfer complexes to catalyse the polymerization of phenylacetylene. Quinones with a LUMO energy greater than ca. $-2 \mathrm{eV}$ are too weak as electron acceptors and do not form a charge-transfer complex with (mesitylene)$\mathrm{Mo}(\mathrm{CO})_{3}$. Quinones with a LUMO energy lower

Table 3

LUMO energies for substituted 1,4-benzoquinones, calculated using semi-empirical methods AM1 and PM3

\begin{tabular}{lll}
\hline Quinone & $\begin{array}{l}\text { AM1 LUMO } \\
\text { energy /eV }\end{array}$ & $\begin{array}{l}\text { PM3 LUMO } \\
\text { energy /eV }\end{array}$ \\
\hline $\begin{array}{l}\text { 2,3,5,6-Tetramethyl-1,4- } \\
\text { benzoquinone }\end{array}$ & -1.513 & -1.491 \\
1,4-Benzoquinone & -1.735 & -1.701 \\
Chloranil & -2.433 & -2.186 \\
Bromanil & -2.549 & -2.279 \\
Fluoranil & -2.738 & -2.706 \\
DDQ & -2.972 & -2.863 \\
\hline
\end{tabular}


than ca. $-2.5 \mathrm{eV}$ are strong electron acceptors and will form a charge-transfer complex with (mesitylene) $\mathrm{Mo}(\mathrm{CO})_{3}$, but these charge-transfer complexes are inactive with respect to the polymerization of phenylacetylene. Only bromanil and chloranil, for which the calculated LUMO energies lie between $-2 \mathrm{eV}$ and -2.5 $\mathrm{eV}$, form charge-transfer complexes with (mesitylene) $\mathrm{Mo}(\mathrm{CO})_{3}$ which catalyse the polymerization of phenylacetylene.

We would suggest that the inactivity of the more stable charge-transfer complexes is due to a significant loss in electron density around the molybdenum centre leading to a reduction in the ability of the metal to bond to ligands through $\pi$-back donation. A previous study on the effect on charge-transfer complexes of (arene)$\mathrm{Cr}(\mathrm{CO})_{3}$ of altering the electron affinity of the electron acceptor also found that different classes of charge-transfer complexes could be defined [9]. For electron acceptors with a high electron affinity (TCNE), the positive charge on the arene ring is sufficiently high for the $\mathrm{Cr}(\mathrm{CO})_{3}$ to act as an electron donor. For electron acceptors with intermediate electron affinity (chloranil and bromanil), the $\mathrm{Cr}(\mathrm{CO})_{3}$ acts as an electron acceptor from the arene. This work is in good agreement with our findings. For the more stable charge-transfer complexes, the loss of electron density around the metal will decrease the stability of the $\eta^{2}$-alkyne complex. Such an intermediate is essential in the catalytic cycle to form polyphenylacetylene. The stability of $\eta^{2}$-alkyne complexes is enhanced for electron rich metals as $\pi$-back donation is critical to their bonding. The importance of $\pi$-back donation is shown by the increased stability of alkyne complexes in which electron withdrawing groups are present on the alkyne [16]. Moreover, $\pi$-back donation is a significant factor in alkyne complexes in leading to the weakening of the alkyne triple bond, cleavage of which is a further essential step in the catalytic cycle.

\section{Acknowledgements}

This work was funded under the Forbairt Basic Research Scheme. We would like to thank Dr. James Hamilton for determining the molecular weight of the polymer and Prof. John J. Rooney for useful discussions.

\section{References}

[1] P.S. Woon, M.F. Farona, J. Polym. Sci. Polym. Chem. Ed. 12 (1974) 1749.

[2] T.A. Vijayaraj, G. Sundararajan, Organometallics 16 (1997) 4940.

[3] D.A. Sweigart, in: V. Twiggy (Ed.), Mechanisms of Inorganic and Organometallic Reactions, Chap. 10, Plenum, New York, 1985.

[4] M.-H. Desbois, D. Astruc, J. Chem. Soc. Chem. Commun., 1988, p. 472.

[5] G. Huttner, E.O. Fischer, R.D. Fischer, O.L. Carter, A.T. McPhail, G.A. Sim, J. Organomet. Chem. 6 (1966) 288.

[6] H. Kobayashi, M. Kobayashi, Y. Kaizu, Bull. Chem. Soc. Jpn. 46 (1973) 3109.

[7] H. Kobayashi, M. Kobayashi, Y. Kaizu, Bull. Chem. Soc. Jpn. 48 (1975) 1222.

[8] H. Kobayashi, K. Kobayashi, Y. Kaizu, Inorg. Chem. 20 (1981) 4135.

[9] P.G. Sennikov, V.A. Kuznetsov, A.N. Egorochkin, N.I Sirotkin, R.G. Nazarova, G.A. Razuvaev, J. Organomet. Chem. 190 (1980) 167.

[10] T.M. Bockman, J.K. Kochi, J. Am. Chem. Soc. 111 (1989) 4669.

[11] T.A. Vijayaraj, G. Sundararajan, Polym. Prep. 35 (1995) 859.

[12] D.G. Carroll, S.P. McGlynn, Inorg. Chem. 7 (1968) 1285.

[13] C.J. Breheny, J.M. Kelly, C. Long, S. O’Keeffe, M.T. Pryce, G. Russell, M.M. Walsh, Organometallics 17 (1998) 3690.

[14] C.J. Breheny, S.M. Draper, F.-W. Grevels, W.E. Klotzbücher, C. Long, M.T. Pryce, G. Russel, Organometallics 15 (1996) 3679.

[15] John J. Rooney, personal communication.

[16] R.H. Crabtree, in: The Organometallic Chemistry of the Transition Metals, 2nd edn., Chap. 5, Wiley, New York, 1994. 